\title{
Google Translate's Rendition of Verb-Subject Structures in Arabic News Reports
}

https://doi.org/10.33806/ijaes.19.1.11

\author{
Mohammad Anwar Al-Taher \\ Zarqa University
}

\begin{abstract}
The present paper attempts to shed light on one of the issues of Arabic-English translation by the Google Translate service. The renditions provided for verb-subject structures in several news reports are compared and contrasted with the originals in order to come up with some rules which could assist in regulating the translation of the basic elements of the Arabic sentence in the above genre. A number of factors are taken into consideration, such as the length of the subject NP and the verb form and function. GT's rendition of news reports may be improved by introducing certain rules associated with number and articles as well as a limited number of reporting verbs.
\end{abstract}

Keywords: Google translate, news reports, Arabic translation

\section{Introduction}

Nowadays, technology is an integral part of almost every aspect of our lives. Smartphones and computers are used around the globe for most human purposes, including communication, learning and business. Translation is no exception but actually another means for all cross-linguistic and cross-cultural interaction. Therefore, translation services need to develop in the same pace of the huge worldly demand for reliable and fast action.

In this regard, the concepts explored by translation theoreticians have centred on CAT (Computer-Assisted Translation), MT (Machine Translation) and TM (Translation Memory). However, it is now so difficult to differentiate between the three, as they are combined in the new systems (Garcia 2010:8). For instance, the prominent TM systems - SDL Trados, Wordfast and Autshumato have added MT to their services (Rensburg 2012:516). These are purchased from their developers and basically depend on the translator's own accumulation of source texts, aligned along their target texts - a process which could take years of hard translation work. Thus, they are very useful for international organizations, saving a great deal of time and effort and maintaining consistency of relevant terms (Al-Didawi 2012:33). The exploration of matches leads to a copy-and-paste process of the required material from the databases to the TT, which would also prevent most typographical errors (Bowker and Fisher 2012:63).

Before the nineties, machine translation was mainly rule-based, for which "computer and translation experts programmed the morphological analysers, the parsers, etc" (Forcada 2010:218). Later, corpus-based machine translation dominated the field and was more easily built. The statistical principle of such a 
system is probability, choosing the highest possible translation within huge "sentence-aligned bilingual corpora" (Forcada 2010:220).

For the purposes of the present study, it is noteworthy that although Arabic is one of the major world languages, it has not received its due attention by the providers of machine translation services. Arabic is among the six official languages of the UN and the native tongue of over 330 million in 22 countries, in addition to its significance for over a billion Muslims throughout the world (Zbib and Soudi 2012:1).

\section{Purpose of the study}

The study aims to examine the rendition of verb-subject structures in a genre which sees huge daily momentum: news reports. Focusing on the very basic sentence pattern $(\mathrm{S} \mathrm{V})$ with frequent reporting and non-reporting verbs can be a point of departure to improve GT's product. The findings of the paper can be of benefit to the users of the service as well as those researchers working on the development of CAT, MT and TM's. Eventually, translators would have to spend less effort and time with such translation tools.

\section{Literature review}

\subsection{Google Translate's strengths}

As the World Wide Web advances and spreads further, new tools arise. Applications like Babel Fish, Bing Translator, Systran and Google Translate are free to all users. Depending on the giant search engine Google, the Google Translate application translates between - at least - 58 languages (Rensburg 2012:515) and can be accessed through web and smartphone interfaces. It does not have to be installed and it is constantly updated. According to Koehn (in Spellman 2011:146), it employs a statistical approach, "analyzing hundreds of millions of natural bilingual text pairs". In other words, GT utilizes "brute mathematics to compare large collections of previously translated documents" (Simonite 2010:21). It does not actually translate, but "detects patterns already found in its databases" (Lanteigne and Husni 2014:15). It is called a smart system because this 'crowdsourcing' makes it constantly improve its performance (Giles 2011). In other words, the more the fed data, the better the translation. These millions of continually expanding language pairs are quickly examined to determine the closest matches for phrases or chunks of 3 or more words (Freedman 2012). That would fulfill several needs of users in terms of vocabulary, idiomatic expressions and, sometimes, sentence-level grammatical structures (Jin 2013:523). GT tools are argued to be "the most mature product of this approach" (Aldhous 2011:26). Yet, it should be borne in mind that "the simpler the syntax, the better the translation" (Rensburg 2012:520).

With regard to content, the programme "deals better with simple sentences in informative types of style" (E1Sheikh 2012:64). More specifically, it is believed by Şahin and Dungan (2014:78) to work well with technical and media texts, less efficiently with legal texts and fail with literary texts. For others, the service has achieved great practical success in "repetitive legal, economic, technical, 
scientific and other texts", which see considerable demand for translation, along with a high level of consistency and quality (Kučiš and Seljan 2014:322). A survey of the translations of PowerPoint slides, a newspaper article and examination paper finds that GT achieves "the highest marks in the component specialized content and terminology" (Rensburg 2012:520). When GT's renditions are judged in three domains: common words, aphorisms and religion, the results support the first one, basically with sentences of short length. GT's performance is said to be better than that of IM Translator (Al-Deek, Al-Kabi, Haidar and Al-Sukhni 2013:3). In addition, upon rendering sentences from the Noble Qur'an equally of the four basic functions (declarative, interrogative, exclamatory, and imperative) into English, the findings clearly indicate that GT's translations are also better than those of Babylon MT system, except in exclamatory Arabic sentences (Al-Sukhni, Al-Kabi and Alsmadi 2016:119).

Studies also show that GT is preferred to traditional dictionaries due to its speed and accuracy, mainly with reference to collocations, phrases, and technical terms, rated as "the second most widely used online tool by language learners because of its convenience" (Darancik 2016:89).

\subsection{Google Translate's weaknesses}

As a machine will definitely not 'comprehend' a text like humans do, there must be several problems with GT's translation. First and foremost, it cannot 'select' the most appropriate synonyms for different contexts (Jin 2013:525), attributed to the use of what is called above "brute mathematics." Second, GT cannot recognize rhyme. Third, it largely cannot tell the endings or morphemes attached to verbs of different conjugations, especially in Arabic. Fourth, it is unable to distinguish Arabic vowelings. Fifth, it cannot address the semantic question of ambiguity (ElSheikh 2012:64). Sixth, the complex morphology and overlap with syntax in the Arabic language could cause the encounter of new forms of words, which such a system may not be able to translate (Habash and Sadat 2012). Other GT's disadvantages are listed in terms of idioms, style (field), word order, diction and rhetoric (Shui-ying 2008). In another study, the inflection of tense, aspect, and modality of verb systems in Arabic is investigated, with most focus on aspect. It is found that the Arabic free word-order system makes it harder for GT's translation, mainly when attempting to "create logical sentence structure in English" (Alasmary, Watson and Atwell 2017:13). More particularly, a paper discusses GT's rendition of Arabic texts by political thinkers Azmi Bishara and Muhammad Hasanayn Haykal, which have a lot to do with the news report genre. Most errors here are related to "relative pronouns, articles, word order, word choice, preposition, transliteration and missing subjects" (Lanteigne and Husni 2014:2425).

As a result, GT's product is considered by many as 'pre-translation' which still needs a lot to be revised (Anggaira and Hadi 2017:14). The application actually allows for human 'post-editing', which assists in the process of selfimprovement. That would, on the other hand, lead to an additional weakness associated with quality, when non-professionals of translation contribute to the 
building of the supposedly 'reliable' data collections stored by the system (Rensburg 2012:516).

\section{Google Translate and news reports}

Mainly due to the frequent use of the genre, news reports are chosen for investigation to be the focus of the study. They are very much widespread and, thus, more likely than many other genres to have gone through machine translation.

News reports are supposed to enjoy four properties (Kharma 1997). Firstly, they should be accurate, by selecting the right way of putting together details, providing precise facts and mentioning correct names, times, dates, etc. Secondly, they should be clear, by making the ideas as easy as possible for the ordinary listener or reader. Thirdly, they should be concise and avoid lengthy explanation. Fourthly, they should be objective, by leaving no or little room for "subjective epithets to describe persons, actions, groups and situations" (Kharma 1997:249).

On the other hand, the translation of news stories is argued to have a number of features (Bielsa and Bassnett 2009:63-68). First, "a clear and direct language" should be used, in order to communicate successfully to mass audiences. Secondly, the transmission of information is the main objective, often adopting a narrative style in which "the author's personal style is reduced to the minimum". Thirdly, the medium of the context has certain limitations associated with time, space and culture.

Such 'expository' texts are believed to 'set a scene' while the word order is hardly manipulated since 'rhetorical effect' is not essentially required (Hatim 1997:51).

Looking at the above points, one can come up to tell the rationale behind choosing news reports for the purpose of measuring and, thus, improving GT's performance. Firstly, 'correctness' facilitates the mission and is expected to reflect in somewhat literal translation. Second, 'Clarity' would also match GT's high performance with 'simpler syntax', in contrast with its weak translation of ambiguity. Thirdly, 'objectivity' - or the absence of subjective portrayals - would relieve the translator of searching for context-specific equivalents. Fourthly, the 'informative' nature of this genre supports clarity and objectivity to fulfill the readership's desire for the acquisition of knowledge. However, as an exception, the temporal, spacial and cultural elements of context could be the only relevant factor that is not very helpful to GT's rendition of news stories. Finally, the genre's consistent word order and the supposedly absent 'rhetorical effect' facilitate the machine translation's task, for there is no complication at the lexical and semantic levels. More broadly, it is noted that "news reports share the same components -headline, lead and body" (Al-Fahad 2012:286).

Based on all the above, and bearing in mind the nature of machines, literal translation can work well for a large proportion of such cases. Here, one can argue that the news report genre seems to be a good option as a point of departure for GT to consider a Rule-based method side by side with the Statistics-based approach. 


\section{Data analysis}

Prior to making a particular proposal, it is necessary to explore the effectiveness of GT's current relevant capability, bearing in mind the advantages and disadvantages stated in Sections 2.1. and 2.2..

\subsection{Methodology}

The methodology adopted in the present study goes as follows:

- News reports (whose headlines and dates are provided in the Appendix) are investigated on the websites of the rival and top ranking Arab channels: AlArabiya and Al-Jazeera, with 306.63 million and 277.88 million visits respectively (Forbes Middle East 2017).

- Each report is wholly copied and pasted to GT to carry out instant translation, employing no post-editing. The process took place in February, 2017.

- Both the ST and TT are aligned in a Word document.

- A hundred examples of the Verb-subject structure of the ST'sand TT's are spotted and underlined. This is the simplest of the 7 sentence patterns: "Type SV: S Vintrasitive" (Quirk, Greenbaum and Leech 1972:343), in which the Subject "has number and person concord, where applicable with the verb phrase" (Quirk et al. 1972:384).Thus, the following cases are excluded: sentences with transitive verbs; passive structures; sentences with 'inna' and sistersor with 'ka:na' and sisters كان وأخواتها'; one-word sentences (i.e. without an explicit, self-standing subject); sentences with the subject and verb separated by other elements; conditional clauses; sentences with helping verbs like تينغي , and بيب ,يمكن ,قام A negative structures; relative clauses; and NP's of two subjects connected with And ' $g$ '.

- The analysis conducted classifies the translations as Satisfactory, Unsatisfactory and Medium. The Unsatisfactory type is associated with the TT structures syntactically unacceptable (e.g. lacking subject, verb or S-V agreement) or semantically different from their ST's. On the other hand, the Medium category mainly has to do with less significant linguistic matters (e.g. definite vs. indefinite articles and singular vs. plural nouns).

\subsection{Results}

The data analysis shows the following results with reference to the originals and translations:

1. Out of the total 100 cases, 52 of the translations are satisfactory, 6 are medium and 42 are unsatisfactory.

2. Of the originals, there are 30 single-word subjects and 70 cases of long subjects. For the translations of the former, 19 (63.33\%) are satisfactory, $3(10 \%)$ are medium, and $8(26.66 \%)$ are unsatisfactory.

قال أوباما إن الو لايات المتحدة تحرص... (1a)

(1b) Obama said the United States is keen... (satisfactory)

وشند المغردون على أن السلطات تنع الزيارات عن المتتقلين (2a) 
(2b) * He stressed that the authorities Amordon prevent visits detainees (unsatisfactory)

For the translations of the latter, $33(47 \%)$ are satisfactory, $3(4.28 \%)$ are medium and $34(48.57 \%)$ are unsatisfactory.

أعلن الرئيس الأميركي بار الك أوباما اليوم الأحد أن المفاوضين الأميركيين و الروس (3a)

(3b) US President Barack Obama said on Sunday that American and Russian negotiators are working "around the clock"(satisfactory)

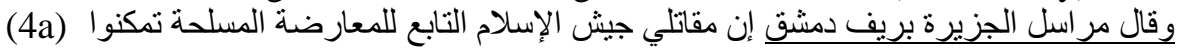

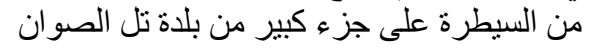

(4b) *The Al-Jazeera correspondent in Rural Damascus that the Army of Islam fighters of the armed opposition have taken control of a large part of the town of Flint Hill (unsatisfactory)

3. Of the originals, there are 62 reporting verbs and 38 non-reporting verbs. For the translations of the former, $39(62.90 \%)$ are satisfactory, $4(6.45 \%)$ are medium and $19(30.64 \%)$ are unsatisfactory.

وذكرت مصادر عسكرية أن أحد التفجيرين أدى إلى مصرع عشرة على الأقل من قوات (5a) الثرطة

(5b) Military sources said that one of the blasts led to at least ten policemen were killed (satisfactory)

وتقول إحدى السائحات الروسيات لمر اسل الجزيرة إنهم كانوا ينتظرون بفارغ الصبر إتاحة (6a)

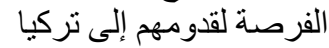

(6b) *She says one of the tourists to the Russian-Jazeera correspondent that they were eagerly awaiting the opportunity to arrival to Turkey (unsatisfactory)

For the translations of the latter, $13(34.21 \%)$ are satisfactory, $2(5.26 \%)$ are medium and $23(60.52 \%)$ are unsatisfactory.

يتجمع زعماء عالميون لحضور اجتماع قمة مجمو عة العشرين(7a)

(7b) World leaders gather to attend the Group of Twenty summit (satisfactory)

اشتعلت مو اقع التو اصل الاجتماعي مجددا ضد الانتهاكات التي تطال المعتقلين السياسيين(8a) (8a)

(8b) *he caught the social networking sites again against violations of political prisoners (unsatisfactory)

4. Of the originals, there are 85 past verbs and 15 present verbs. For the translations of the former, $49(57.64 \%)$ are satisfactory, $5(5.88 \%)$ are medium and $31(36.47 \%)$ are unsatisfactory.

أفاد ناشطون بأن طائر ات روسية وسورية شنت غار ات على أحياء حلب(9a)

(9b) activists reported that Syrian and Russian planes carried out raids on districts of Aleppo (satisfactory)

و أتت إقالة وزير الدفاع بُعْد ساعات من تمكن الجيش من استعادة السبطرة على مدينة بوني(10a)

(10b) * And it brought the dismissal of the defense minister hours after the army managed to regain control of the city of Pune (unsatisfactory)

For the translations of the latter, $3(20 \%)$ are satisfactory, $1(6.66 \%)$ is medium and $11(73.33 \%)$ are unsatisfactory.

تدور معارك عنيفة مع الحوثيين و أنصار الرئيس المخلوع علي عبد الله صالح بالمنطقة (11a) 
(11b) there are fierce battles with the rebels and supporters of ousted President Ali Abdullah Saleh in the region. (satisfactory)

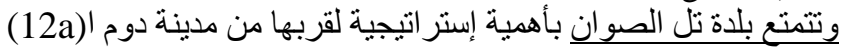

(12b) *And enjoy the town of Tel flint strategically important because of its proximity to the city always (unsatisfactory)

The following table summarizes the results with reference to the above three elements.

Table 1: Translation assessment of ST sentences with differences in subject length, reporting and tense

\begin{tabular}{|c|c|c|c|c|}
\hline \multirow{2}{*}{\multicolumn{2}{|c|}{ Area of difference }} & \multicolumn{3}{|c|}{ Translation assessment (\%) } \\
\hline & & Satisfactory & Medium & Unsatisfactory \\
\hline \multirow[t]{2}{*}{$\begin{array}{l}\text { Subject } \\
\text { length }\end{array}$} & $\begin{array}{l}\text { Single-word } \\
(30 \text { cases })\end{array}$ & 63.33 & 10 & 26.66 \\
\hline & $\begin{array}{l}\text { Long } \\
\text { (70 cases) }\end{array}$ & 47 & 4.28 & 48.57 \\
\hline \multirow[t]{2}{*}{ Reporting } & $\begin{array}{l}\text { Reporting } \\
\text { (62 cases) }\end{array}$ & 62.90 & 6.45 & 30.64 \\
\hline & $\begin{array}{l}\text { Non-reporting } \\
\text { (38 cases) }\end{array}$ & 34.21 & 5.26 & 60.52 \\
\hline \multirow[t]{2}{*}{ Tense } & $\begin{array}{l}\text { Past } \\
(85 \text { cases })\end{array}$ & 57.64 & 5.88 & 36.47 \\
\hline & $\begin{array}{l}\text { Present } \\
(15 \text { cases })\end{array}$ & 20 & 6.66 & 73.33 \\
\hline
\end{tabular}

5. Of the originals, there are no cases to be mentioned of rhyme, ambiguity or rhetoric.

6. Of the translations, there are 11 unsatisfactory cases of two subjects placed around the main verb, mainly attributed to Arabic verb conjugations.

سيطرت المعارضة المسلحة على مو اقع إستر اتيجية في الغوطة الثرقية بريف دمشق(13a)

(13b) *It seized control of the armed opposition on strategic locations in the eastern Ghouta Damascus countryside(unsatisfactory)

7. Of the translations, there are 3 unsatisfactory cases of derivation, purely attributed to Arabic vowelings.

و وتفاءَل الأتر الك باستنناف تدفق السياح الروس إلى بلادهم(14a)

(14b) *Turks and optimism to resume the flow of Russian tourists to their country (unsatisfactory)

8. Of the translations, there are 13unsatisfactorycases related to word order, made up of verb-subject structures.

ونأتي هذه المسيرة تز امنا مع مسير ات مماثلة شهدتها مدن أخرى(15a)

(15b) *Comes this march to coincide with similar rallies seen in other cities (unsatisfactory) 
9. Of the translations, there are 3 medium cases which confuse definite and indefinite articles.

$$
\text { وقال المصدر العكري الكردي لرويترز إن "العمليات العسكرية لقوات سوريا الديمقرالية (16a) تجري الآن }
$$

(16b) *A Kurdish military source told Reuters that "the military operations of the Democratic Forces for Syria are under way (medium)

10. Of the translations, there are 10 unsatisfactory cases because they contain $n o$ verbs.

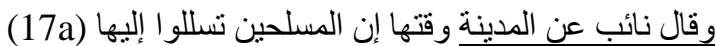

(17b) *The deputy city at the time that the gunmen had infiltrated them (unsatisfactory)

11. Of the translations, there are 2 unsatisfactory cases with the subject NP split around the main verb.

وتقول سامنثا باور رئيسة الوفد "عندما نتحدث عن إرسال أربعة آلاف من قوات إضافية (18a)

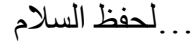

(18b) * Samantha Power, says head of the delegation, "When we talk about sending four thousand additional troops for peacekeeping forces (unsatisfactory)

12. Of the translations, there is a single medium case which uses the plural ' $s$ ' with a singular noun.

وفق ما أفاد مصدر عسكري كردي الثلاثاء... (19a)

(19b) *a Kurdish military sources said Tuesday (medium)

\section{Conclusion}

Based on their matching results above, the following points can be concluded:

1. The satisfactory $52 \%$ and medium $6 \%$ translations fairly indicate GT's mediocre success in rendering Arabic sentences of news reports, where "the most mature" programme is expected to "work well."

2. The single-word subject NP's translations' failure by only $26.66 \%$ in contrast with $48.57 \%$ by the translations of long NP's confirms the proposition that "the simpler the syntax, the better the translation." This could tell users that the more complicated sentences and phrases, the less trust they should have in GT.

3. The translations of sentences containing reporting verbs, which constitute an integral of news reports, make a big difference from those with other verbs by $62 \%$ to $34.21 \%$. The result confirms the notion that GT works better with 'repetitive' texts, as 'the statistical approach' attempts to find matches for 'chunks'.

4. The unsatisfactory renditions of constructions in the past are also disparate from those in the present by $36.47 \%$ to $73.33 \%$, somewhat similarly to the previous point as both associate with the phrasing of news reports.

5. The lack of rhyme, rhetoric and semantic ambiguity in the source texts has to do with the genre's major features of clarity and objectivity.

$6+7$. Due to its multi-functional nature, the Arabic morpheme ' $ت$ ' causes a great deal of confusion for GT. As a prefix, on the one hand, it could make a noun (e.g. (تقسيم), a feminine third-person singular present verb (e.g. (تُقسّم (هي), a masculine 
second-person present verb (e.g. تُقسِّم (أنت) past verb (e.g. تَقاسََ ). On the other hand, as a suffix, it could make several past verbs, like that which is feminine third-person singular (e.g. ذكرَتْ

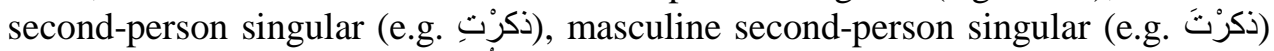
and first-person singular (e.g. ذكرْتُّ). Thus, the vowelings for one or more of the letters in such words need to be added, if possible, to avoid this type of morphological ambiguity in the Arabic language. Such nature of conjugations and vowelings adds to the complicated task of the GT service.

8. As there are 13 English verb-subject constructions among the renditions, it could be assumed that no matches have been found by GT for these particular word chunks. Thus, word-for-word translation seems to be automatically adopted. 9. As for definite and indefinite articles, the statistical method again applies. Yet, to fail to translate only $3 \%$ of verb-subject constructions shows a high success of GT, bearing in mind that the Arabic ال 'the' is a bound morpheme while the English 'the' 'a' and 'an' are free morphemes.

10. With reference to the absence of the verb in the translations of 11 cases, one cannot think of a justification for not finding matches for such a main element. قال 'said', أكد 'confirmed or stressed' and كثنف 'uncovered or revealed'.

11. The 2 examples of NP's split around the verb reveal that there may be a tendency of GT, due to the "large collection of data", to pre-pose the subject and/or post-pose the verb. However, the machine is still incapable of differentiating between such elements in order to 'chunk' NP's and VP's correctly like humans do. That is perhaps attributed again to the 'simpler syntax' required for a successful GT rendition.

12. As there is only a single case of verb-subject concord problem in English, the huge "bilingual text pairs" seem not to find a good match for that particular 3word subject NP with a common reporting verb أفاد 'reported'.

Finally, the following analysis paves the way for a proposed formula to translate the fundamental components of a typical sentence in an Arabic news report ((و) 'and' + Verb + Subject) into English.

Component 1 (و) is often found at the outset of all the paragraphs of a news report except the lead, if any, and the initial one. Since 'and' does not serve the Arabic 'resumption' function of the (9), it is naturally omitted in English.

Component 2 (Verb) could often refer to a limited list of reporting verbs, (such as قال، أعلن، أشار، ذكر، كثف، نقل، أفاد، صرّح، أضاف، أكد، أعرب، شدد، اعتبر، أوضح)، These fairly literally mean 'said', 'announced', 'remarked', 'mentioned', 'revealed', 'reported', 'reported', 'declared', 'added', 'confirmed or stressed', 'expressed or voiced', 'stressed', 'considered', and 'explained' respectively. They might also take a present form, for which the English verb must be ended in ' $s$ ' if the subject is third-person singular (typically not ending in ' $\mathrm{s}$ '). A similar possibility is the presence of the $(ت)$ to indicate a feminine subject as a prefix for of a present verb or a suffix for a past verb.

Component 3 (Subject) needs to be explicit for the purposes of the present study as a first step. If the Arabic subject is implied, further morphological and 
syntactic complications shall arise. Certainly, the subject must be shifted to an initial position in the English sentence, taking into consideration the addition of 'the' for an Arabic definite noun with ال or 'a/an' for other cases. As frequently found earlier, single-word subjects are much easier to apply.

The Figure below shows 16 major possibilities for translations which combine rule-based and statistic-based systems, considering past vs. present verbs; masculine vs. feminine verbs and subjects; singular vs. plural nouns; and definite vs. indefinite nouns. On the other hand, the subject is definitely shifted to an initial position, followed by the verb which achieves concord when necessary.

Figure

Proposed initial formula to translate the basic elements of a typical Arabic news report sentence into English

1. e.g. و' ' و وقال المصدر + pas. mas. V. + def. sing. mas. S.

$=$ def. art. + sing. S.+ pas. V. (e.g. The source said)

2. (e.g. و' ' وقال مصدر + pas. mas. V. + indef. Sing. mas. S.

$=$ indef. art. + sing. S. + pas. V. (e.g. A source said)

3. (e.g. و ' ' وقالت المر اسلة + pas. fem. V. + def. sing. fem. S.

$=$ def. art. + sing. S. + pas. V. (e.g. The reporter said)

4. (e.g. و' ' وقالت مر اسلة + pas. fem. V. + indef. sing. fem. S.

$=$ indef. art. + sing. S. + pas. V. (e.g. A reporter said)

5. (e.g. و' ' و وقالت الدصادر + pas. fem. V. + def. pl. (fem.) S.

$=$ def. art. + pl. S. + pas. V. (e.g. The sources said)

6. (e.g. و' و وقالت مصادر + و + pas. fem. V. + indef. pl. (fem.) S.

$=$ zero art. + pl. S. + pas. V. (e.g. Sources said)

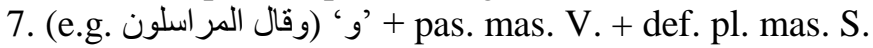

$=$ def. art. + pl. S. + pas. V. (e.g. The reporters said)

8. (e.g. و' ' وقال مر اسلون + pas. mas. V. + indef. pl. mas. S.

$=$ zero art. + pl. S. + pas. V. (e.g. Reporters said)

9. (e.g. و' ' و ' + pres. mas. V. + def. sing. mas. S.

$=$ def. art. + sing. S. + pres. V (with - s). (e.g. The source says)

10. (e.g. ويقول مصدر + 'و + pres. mas. V. + indef. Sing. mas. S.

$=$ indef. art. + sing. S. + pres. V (with - s). (e.g. A source says)

11. (e.g. و' 'وتقول المر اسلة + pres. fem. V. + def. sing. fem. S.

$=$ def. art. + sing. S. + pres. V (with - s). (e.g. The reporter says)

12. (e.g. و' 'و ' وتقول مر اسلة + pres. fem. V. + indef. sing. fem. S.

$=$ indef. art. + sing. S. + pres. V(with - s). (e.g. A reporter says)

13. (e.g. و' ' وتقول المصاد + pres. fem. V. + def. pl. (fem.) S.

$=$ def. art. + pl. S. + pres. inf. V. (e.g. The sources say)

14. (e.g. و' 'و 'و + ول مصادر + pres. fem. V. + indef. pl. (fem.) S.

$=$ zero art. + pl. S. + pres. inf. V. (e.g. Sources say)

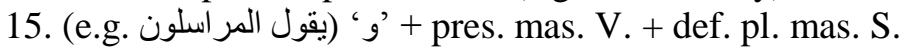

$=$ def. art. + pl. S. + pres. inf. V. (e.g. The reporters say)

16. (e.g. ويقول مر اسلون + ' + pres. mas. V. + indef. pl. mas. S.

$=$ zero art. + pl. S. + pres. inf. V. (e.g. Reporters say)*. 
*The researcher would like to voice gratitude to Zarqa University for funding this research.

Mohammad Anwar Al-Taher (PhD)

Assistant Professor

Department of English Language, Literature \& Translation

Zarqa University

Zarqa, 132222

Jordan

E-mail: tahers1@yahoo.com 


\section{References}

Alasmari, Jawharah, Janet Watson and Eric Atwell. (2017). 'A comparative analysis between Arabic and English of the verbal system using Google Translate'. International Journal on Islamic Applications in Computer Science and Technology, 5 (3): 9-14.

Al-Deek, Hadeel, Mohammad Al-Kabi, Mohammad Haidar and Emad AlSukhni. (2013). 'Automatic evaluation for Google Translate and IMTranslator translators: An Empirical English-Arabic Translation'. The 4th International Conference on Information and Communication Systems. Irbid, Jordan.

Aldhous, Peter. (2011). 'Google's data junkie...Peter Norvig'. New Scientist, 210(2810): 26-27.

Al-Didawi, Mohammad. (2000). Al-Tarjamah wa Al-Tawasul [Translation and Communication]. Casablanca: Arab Cultural Center.

Al-Fahad, Saleem. (2012). 'Aspects governing effectiveness in translating Arabic news reports into English: an analytical study'. In Aladdin Jrab (ed.), Perspectives on Contemporary Academic Research, 280-289. Zarqa: Zarqa University.

AlSukhni, Emad, Mohammad Al-Kabi and Izzat Alsmadi. (2013). 'An Automatic Evaluation for Online Machine Translation: Holy Quran Case Study'. International Journal of Advanced Computer Science and Applications, 7 (6): 118 -123.

Anggaira, Aria Septi and Muhamad Sofian Hadi. (2017). 'Linguistic errors on narrative text translation using Google Translate'. Journal of English Language Teaching. 5 (1): 1-14.

Bielsa, Esparanca and Susanne Bassnett. (2009). Translation in Global News. London: Routledge.

Bowker, Lynne and Des Fisher. (2010). 'Computer-aided translation'. In Yves Gambier and Luck van Doorsler (ed.), Handbook of Translation Studies, 60-65. Amsterdam: John Benjamins Publishing Company.

Darancik, Yasemin. (2016). 'The effect of data-based translation program used in foreign language education on the correct use of language'. The Turkish Online Journal of Educational Technology, 15(4): 88-106.

ElSheikh, Ahmed. (2012). 'Google Translate service: transfer of meaning, distortion or simply a new creation'. English Language and Literature Studies, 2(1): 56-68.

Forbes Middle East Lists. (2016). Top TV Channels Online In The Arab World. https://www.forbesmiddleeast.com/en/list/top-tv-channels-online-in-thearab-world/ (Retrieved on 6 July, 2018).

Forcada, Mikel. (2010). 'Machine translation today'. In Yves Gambier and Luck van Doorsler (ed.), Handbook of Translation Studies, 215-223. Amsterdam: John Benjamins Publishing Company. 
Freedman, David. (2012). Impatient Futurist: Good News, Spock-We're Getting Closer to a Universal Translator. Waukesha: Discover Magazine.http://discovermagazine.com/2012/mar/06-impatient-futuristgood-news-universal-translator (Retrieved on 15 December, 2017)

Garcia, Ignacio. (2010). 'Is machine translation ready yet'. Target, 22(1): 7-21.

Giles, Jim and Jacob Aron. (2011). 'The world will understand'. New Scientist, 209(2802): 25-26.

Habash, Nizar and Fatiha Sadat. (2012). 'Arabic preprocessing for statistical machine translation: schemes, techniques and combinations'. In Rabih Zbib and Abdelhadi Soudi (ed.), Challenges for Arabic Machine Translation, 7394. Amsterdam: John Benjamins Publishing Company.

Hatim, Basil. (1997). English-Arabic/Arabic English Translation: A Practical Guide. London: Saqi Books.

Jin, Li. (2013). 'Foreign language learners' use and perception of online dictionaries: a survey study'. MERLOT Journal of Online Learning and Teaching, 9(4): 515-533.

Kharma, Nayef. (1997). Translation II. Amman: Al-Quds Open University Press.

Kučiš, Vlasta and Sanja Seljan. (2014). 'The role of online translation tools in language education'. Babel, 60(3): 303-324.

Lanteigne, Betty and Ronak Husni. (2014). 'Characteristics of Arabic text Google translated to English: an error analysis'. Turjuman. 23(1): 11-38.

Quirk, Randolf, Sidney Greenbaum and Geoffrey Leech. (1972). A Grammar of Contemporary English. London: Longman.

Rensburg, Alta, Cobus Snyman and Susan Lotz. (2012). 'Applying Google Translate in a higher education environment: translation products assessed'. Southern African Linguistics and Applied Language Studies, 30(4): 511524.

Şahin, Mehmet and Nilgün Dungan. (2014). 'Translation testing and evaluation: a study on methods and needs'. Translating and Interpreting, 6(2): 67-90.

Shui-ying, Cheng. (2008). 'Understanding and improving online statistical translation methods'. Sino-US English Teaching, 5(9): 38-45.

Simonite, Tom. (2010). 'Are machines ready to break down language barriers'. New Scientist, 205(2752): 5-65.

Spellman, Rosemary. (2011). 'Developing best practices for machine translation using Google Translate and OCR terminal'. Journal of Interlibrary Loan, Document Delivery \& Electronic Reserve, 21(1): 141-147.

Zbib, Rabih and Abdelhadi Soudi. (2012). Challenges for Arabic Machine Translation. Amsterdam: John Benjamins Publishing Company. 
Appendix: Analyzed news reports

1. أوباما: لدينا خلافات خطبرة بالملف السوري مع موسكو، الجزيرة، 2016/9/4.

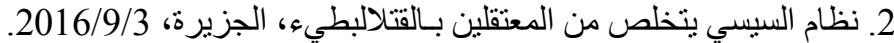

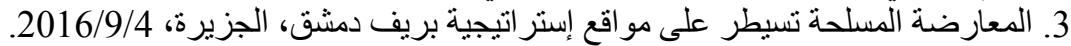

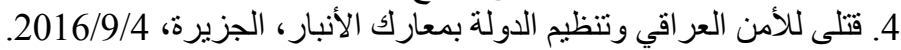
5. السياح الروس يعودون لتركيا بعد أنشهر من القطيعة، الجزيرة، الجيرة، 2016/9/3.

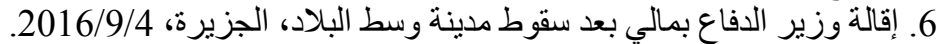

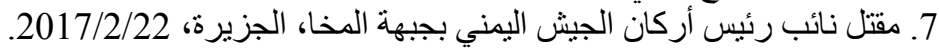

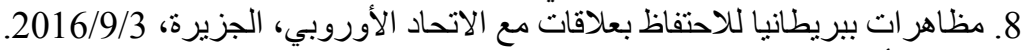

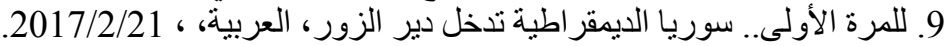

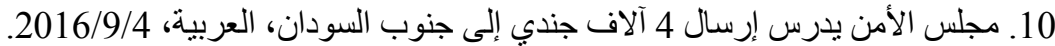

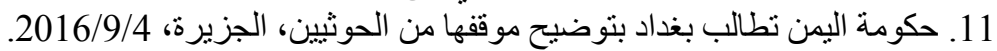

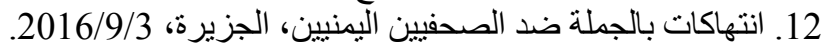

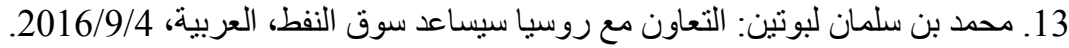
14. نائب إير اني: خامنئي هو من منح قاعدة هددان للروس، العربية، 2016/9/3. 